\title{
DESIGN, FABRICATION AND PERFORMANCE ANALYSIS OF A MIXED MODE SOLAR DRYER FOR DRYING VEGETABLES.
}

\author{
Resha Taide $^{1} \&$ Dr. S. J. Deshmukh ${ }^{2}$
}

Abstract-A study on performance of solar dryer was carried out, it involved; design, fabrication, testing and studying the drying kinetics of a solar dryer. A natural convection mixed-mode solar dryer was used for drying vegetables with the intention of maintaining the colour, minimising drying time and increasing the shelf-life.The results obtained from the experiments conducted in the month of May revealed that the temperatures inside the dryer and solar collector were much higher than the ambient temperature during most of the day-light. The optimum temperature of the solar flat plate collector was $74^{\circ} \mathrm{C}$ and that of drying chamber was $56^{2} \mathrm{C}$ with corresponding ambient temperature of $42^{\circ} \mathrm{C}$. Thermal efficiency of solar collector was found to be $38 \%$.The system drying efficiency of solar dryer was found to be $\mathbf{1 5 \%}$. The dryer reveals its ability to dry food items rapidly to a safe moisture level. It can be used to replace electrical and conventional dryer in semi-urban and rural areas of India.

Keywords - Mixed mode solar dryer, Solar energy,temperature,solar collector, drying cabinet,drying time,moisture content.

\section{INTRODUCTION}

Solar food drying is one of the oldest agricultural techniques related to food preservation but every year millions of dollars worth of gross national product is lost through spoilage. Reasons include ignorance about preservation of produce, inadequate transportation system during harvest season and low price the rural farmer receives for products during harvest season. Drying of crop can change this trend and is useful in the area of world especially those without high humidity during the harvesting season. If drying of produce is widely implemented significant saving to farmer would be achieved. These savings could help strengthen the economic situation of numerous developing government as well as change the nutritional condition in these same countries. Unfortunately many of these areas that could be benefit from solar drying technology lack adequate information related to how to employ this technology and which technology to use under specific condition. Drying preserves food by removing enough moisture from food to prevent decay and spoilage. When drying foods, the key is to remove moisture as quickly as possible at a temperature that does not seriously affect the flavour, texture and colour of the food. Microorganisms are effectively killed when the internal temperature of food reaches $40-60^{\circ} \mathrm{C}$. The flavor and most of the nutritional value of dried food is preserved and concentrated. Dried foods do not require any special storage equipment and are easy to transport. Dehydration of vegetables and other food crop by traditional methods of open-air sun drying is not satisfactory, because the products deteriorate rapidly. Studies showed that food items dried in a solar dryer were superior to those which are sun dried when evaluated in terms of taste, color and mold counts. Solar dried food are quality products that can be stored for extended periods, easily transported at less cost while still providing excellent nutritive value. This study work therefore presents the design and construction of a domestic passive solar food dryer. Food materials and crops are very sensitive to the drying conditions. Thus the selection of drying temperature is one of the most important things to ensure the color, texture, flavor and value of the product will not degrade. Thereby, a new design of high efficiency solar dryer for small scale food was designed and tested for vegetables. Drying result obtained was compared with the result of the naturally direct sun-dried product.

\section{BASIC THEORY:}

The energy balance on the absorber is obtained by equating the total heat gained to the total heat loosed by the heat absorber of the solar collector. Therefore,

$\mathrm{IAc}=\mathrm{Qu}+\mathrm{Qcond}+\mathrm{Qconv}+\mathrm{QR}+\mathrm{Q} \rho$

Where: $\mathrm{I}=$ rate of total radiation incident on the absorber's surface $(\mathrm{Wm}-2)$;

Ac $=$ collector area $\left(\mathrm{m}^{2}\right)$;

$\mathrm{Qu}=$ rate of useful energy collected by the air $(\mathrm{W})$;

Qcond = rate of conduction losses from the absorber (W);

$\mathrm{Qconv}=$ rate of convective losses from the absorber $(\mathrm{W})$;

$\mathrm{QR}=$ rate of long wave re-radiation from the absorber $(\mathrm{W})$;

\footnotetext{
${ }^{1}$ Department of Mechanical Engineering, PRMIT \& R, Badnera, MAHARASHTRA INDIA
}

${ }^{2}$ Department of Mechanical Engineering, PRMIT \& R, Badnera, MAHARASHTRA INDIA 
$\mathrm{Q} \rho=$ rate of reflection losses from the absorber $(\mathrm{W})$.

The three heat loss terms Qcond, Qconv and QR are usually combined into one-term (QL)

i.e., $\mathrm{QL}=\mathrm{Qcond}+\mathrm{Qconv}+\mathrm{QR}$.

If $\tau$ is the transmittance of the top glazing and IT is the total solar radiation incident on the top surface, therefore,

$\mathrm{IAc}=\tau$ ITAc

The reflected energy from the absorber is given by the expression:

$\mathrm{Q} \rho=\rho \tau$ ITAc

Where $\rho$ is the reflection coefficient of the absorber. Substitution of Eqs. (2), (3) and (4) in Eq. (1) yields:

$\tau \mathrm{ITAc}=\mathrm{Qu}+\mathrm{QL}+\rho \tau \mathrm{ITAc}$, or

$\mathrm{Qu}=\tau \operatorname{ITAc}(1-\rho)-\mathrm{QL}$

For an absorber $(1-\rho)=\alpha$ and hence,

$\mathrm{Qu}=(\alpha \tau)$ ITAc- $\mathrm{QL}$

Where $\alpha$ is solar absorbance. QL composed of different convection and radiation parts. It is presented in the following form

(Bansal et al. 1990):

$\mathrm{QL}=\mathrm{ULAc}(\mathrm{Tc}-\mathrm{Ta})$,

Where:

$\mathrm{UL}=$ overall heat transfer coefficient of the absorber $(\mathrm{Wm}-2 \mathrm{~K}-1)$;

$\mathrm{Tc}=$ temperature of the collector's absorber $(\mathrm{K})$;

$\mathrm{Ta}=$ ambient air temperature $(\mathrm{K})$.

From Equations (5) and (6) the useful energy gained by the collector is expressed as:

$\mathrm{Qu}=(\alpha \tau)$ ITAc - ULAc $(\mathrm{Tc}-\mathrm{Ta})$

Therefore, the energy per unit area (qu) of the collector is

$\mathrm{qu}=(\alpha \tau) \mathrm{IT}-\mathrm{UL}(\mathrm{Tc}-\mathrm{Ta})$

If the heated air leaving the collector is at collector temperature, the heat gained by the air $\mathrm{Qg}$ is:

$\mathrm{Qg}=m_{\alpha} \cdot \mathrm{Cpa}(\mathrm{Tc}-\mathrm{Ta})$,

Where:

$m a .=$ mass of air leaving the dryer per unit time $(\mathrm{kgs}-1)$;

$\mathrm{Cpa}=$ specific heat capacity of air $(\mathrm{kJkg}-1 \mathrm{~K}-1)$.

The collector heat removal factor, $F_{R}$, is the quantity that relates the actual useful energy gained of a collector, Eq. (7), to the useful gained by the air, Eq. (9). Therefore,

$F_{R}=\frac{m_{a} C_{p}\left(T_{c}-T_{a}\right.}{A_{c}\left[a \tau I_{T}-U_{L}\left(T_{c}-T_{a}\right)\right]}$

$\mathrm{Q}_{\mathrm{g}}=\mathrm{A}_{\mathrm{c}} \mathrm{F}_{\mathrm{R}}\left[(\alpha \tau) \mathrm{I}_{\mathrm{T}}-\mathrm{U}_{\mathrm{L}} \mathrm{A}_{\mathrm{c}}\left(\mathrm{T}_{\mathrm{c}}-\mathrm{T}_{\mathrm{a}}\right)\right]$

The thermal efficiency of the collector is defined as (Itodo et al. 2002) is given in

$\eta_{\mathrm{g}}=\frac{\mathrm{Q}_{\mathrm{B}}}{\mathrm{IA} \mathrm{A}_{\mathrm{E}}}$

\section{MATERIALS AND METHOD}

The solar dryer considered is an indirect forced convection solar dryer. In this method the atmospheric air is heated in flat plate collector or concentrated type solar collector. This hot air then flow in the drying cabinet where products are stored. Therefore moisture from the product is lost by convection and diffusion. A typical indirect solar dryer is made up of the following basic units.

\subsection{Collector (Air Heater):}

A flat plate collector is used since it is easy to fabricate and also economical. The collector was constructed using plywood, galvanized iron sheet, clear glass which were locally available with low cost. The collector is made up of wood. GI sheet of $27 \mathrm{~mm}$ guage is used as absorber as it is a good conductor and economical. It is painted black to increase the absorption of heat. The recommended air gap of $7 \mathrm{~cm}$ was selected. The insulating material was selected to be plywood as it is a good insulator as well as environmentally friendly. It also does not have any carcinogenic effects which other popular insulating materials like glass wool have. The collector glazing is $7 \mathrm{~mm}$ thick. One end of the solar collector has an air inlet vent of air and the other end opens to the drying chamber.

\subsection{The Drying Cabinet:}

The drying cabinet together with the structural frame of the dryer was built from well-seasoned woods which could withstand termite and atmospheric attacks. An outlet vent was provided toward the upper end at the back of the cabinet to facilitate and control the convection flow of air through the dryer. Access door to the drying chamber was also provided at the back of the cabinet. This consists of two removable wooden panels made of plywood. The roof of the cabinet was covered with transparent glass sheets of $5 \mathrm{~mm}$ thick, which provided additional heating. To avoid moisture absorption by wood aluminum foil is wrapped on the inside of the chamber. 


\subsection{Drying Trays:}

The drying trays are contained inside the drying chamber and were constructed from a galvanized wire mesh with a fairly open structure to allow drying air to pass through the food items.

\section{PERFORMANCE AND DATA ANALYSES:}

\subsection{Collector efficiency}

Collector efficiency measures the thermal performance, i.e. the useful energy gain of the collector. Not all of the solar radiation from the sun incident on the collector surface is converted to heat. Part of the radiation is reflected back to the sky and the other component is absorbed by the glazing. Once the collector absorbs heat and as a result temperature gets higher than the surrounding, there will also be a heat loss to the atmosphere by convection and radiation

Collector Efficiency, $\eta \mathrm{c}=\frac{M_{a}\left(T_{0}-T_{\mathrm{i}}\right) c_{p}}{I_{c} \eta_{\mathrm{c}}}$

where:

$\bar{v}$ - volumetric flow rate of air, $\mathrm{m} 3 / \mathrm{s}$

$\dot{\rho}-$ air density, $\mathrm{kg} / \mathrm{m} 3$

$\mathrm{T}$ - air temperature elevation, ${ }^{\circ} \mathrm{C}$

$\mathrm{Cp}$ - air specific capacity, $\mathrm{J} / \mathrm{kg}^{\circ} \mathrm{C}$

Ic - insolation on collector surface, $\mathrm{W} / \mathrm{m}^{2}$

Ac - collector area, $\mathrm{m}^{2}$

4.2 Moisture content

Moisture content was taken at the beginning and at the end of each drying day drying and calculated using the following equation:

Moisture content $=\frac{\mathrm{M}_{\mathrm{i}}-\mathrm{MM}_{F}}{M_{\bar{i}}} \times 100$

where:

$\mathrm{Mi}=$ Mass of vegetables slides before drying

Mf $=$ Mass of vegetable slides after drying

\subsection{Drying Rate}

Drying rate is the amount of evaporated moisture over time

$\mathrm{DR}=\frac{M_{\mathrm{i}}-M_{d}}{t}$

where,

$M_{i}=$ mass of sample before drying.

$\mathrm{M}_{\mathrm{d}}=$ mass of sample after drying

$\mathrm{t}=$ drying period.

\subsection{Drying Efficiency}

Drying efficiency is the ratio of the energy needed to evaporate moisture from the material to the heat supplied to the dryer. This term is used to measure the overall effectiveness of a drying system. But it may not be used for comparing one dryer with another due to different factors such as the particular material being dried, the air temperature and mode of air flow may differ for various dryers

System efficiency can be expressed mathematically as

$\eta_{\mathrm{d}}=\frac{\mathrm{ML}}{\mathrm{I}_{\mathrm{t}} \mathrm{A}_{\mathrm{C}}}$

Where,

$\mathrm{M}=$ mass of moisture evaporated per second $(\mathrm{kg} / \mathrm{s})$

$\mathrm{L}=$ latent heat of evaporation of water $(\mathrm{kJ} / \mathrm{kg})$

It $=$ insolation on tilted collector surface $(\mathrm{W} / \mathrm{m} 2)$

$\mathrm{Ac}=$ collector area $(\mathrm{m} 2)$

\subsection{Amount of Moisture to be removed}

The formula to calculate the total amount of moisture to be removed $(\mathrm{Mw})$ is given by Bassey and Schmidt as:

$\mathrm{M}_{\mathrm{m}}=\frac{\mathrm{W}_{\mathrm{w}}\left(\mathrm{M}_{\mathrm{i}} \%-\mathrm{M}_{\mathrm{f}} \%\right)}{1-\mathrm{M}_{\mathrm{f}}}$

where,

$\mathrm{Mw}=$ amount of moisture removed

$\mathrm{Ww}=$ initial total weight; 
$\mathrm{Mi}=$ initial moisture content on wet basis;

$\mathrm{Mf}=$ the final moisture content on wet basis

Amount of heat required to remove moisture content is given by,

$\mathrm{QR}=\left(\mathrm{M}_{\mathrm{m}} \times \mathrm{h}_{\mathrm{fg}}\right)+\left(\mathrm{M}_{\mathrm{m}} \times \mathrm{h}_{\mathrm{f}}\right)$

Where,

$\mathrm{h}_{\mathrm{fg}}=$ Latent heat of evaporations of water.

$h_{f}=$ Enthalpy of water.

\section{EVALUATION OF THE DRYER:}

Evaluation of the dryer was centred on the temperature variations and moisture. The testing of the solar dryer was done in the month of May from 10:00 am to 6:00 pm. The solar .Dryer was placed outside with the collector facing the direction of the sun. The collector is placed inclined to the horizontal to obtain approximately perpendicular beam of sun rays to avoid damage in transit. 100gm fresh green chillies, bitter gourd were placed in solar dryer and 100gm chillies, bitter gourd in the open sun.

\section{RESULTS \& DISCUSSION:}

The hourly variation of the temperatures in the solar collector and the drying cabinet compared to the ambient temperature. It was observed that the vegetables (such as chilies, bitter gourd) placed in solar dryer had a faster rate of drying than the vegetables placed in the open sun. 8hrs of drying time was required for the chillies in solar dryer to reach the equilibrium drying stage whereas $10 \mathrm{hrs}$ of drying was required by the chilies placed in open sun. Similar observation was noted in case of other vegetables. Bitter-gourd placed in solar dryer took $6 \mathrm{hrs}$ of drying whereas it took $8 \mathrm{hrs}$ of drying in open sun. This shows that the solar dryer had a faster rate of drying than the vegetables in the open sun drying method. This indicates that the dryer exhibits sufficient ability to dry vegetable items at a reasonably rapid rate. The thermal efficiency of solar collector and the drying rate increase and decrease with the rise and fall of temperature. Thermal efficiency of solar collector was found to be $38 \%$. The system drying efficiency of solar dryer was found to be $15 \%$. Drying rate chilli, bitter gourd were found to be $10.75 \mathrm{~g} / \mathrm{hr}, 14.6 \mathrm{~g} / \mathrm{hr}$ respectively.

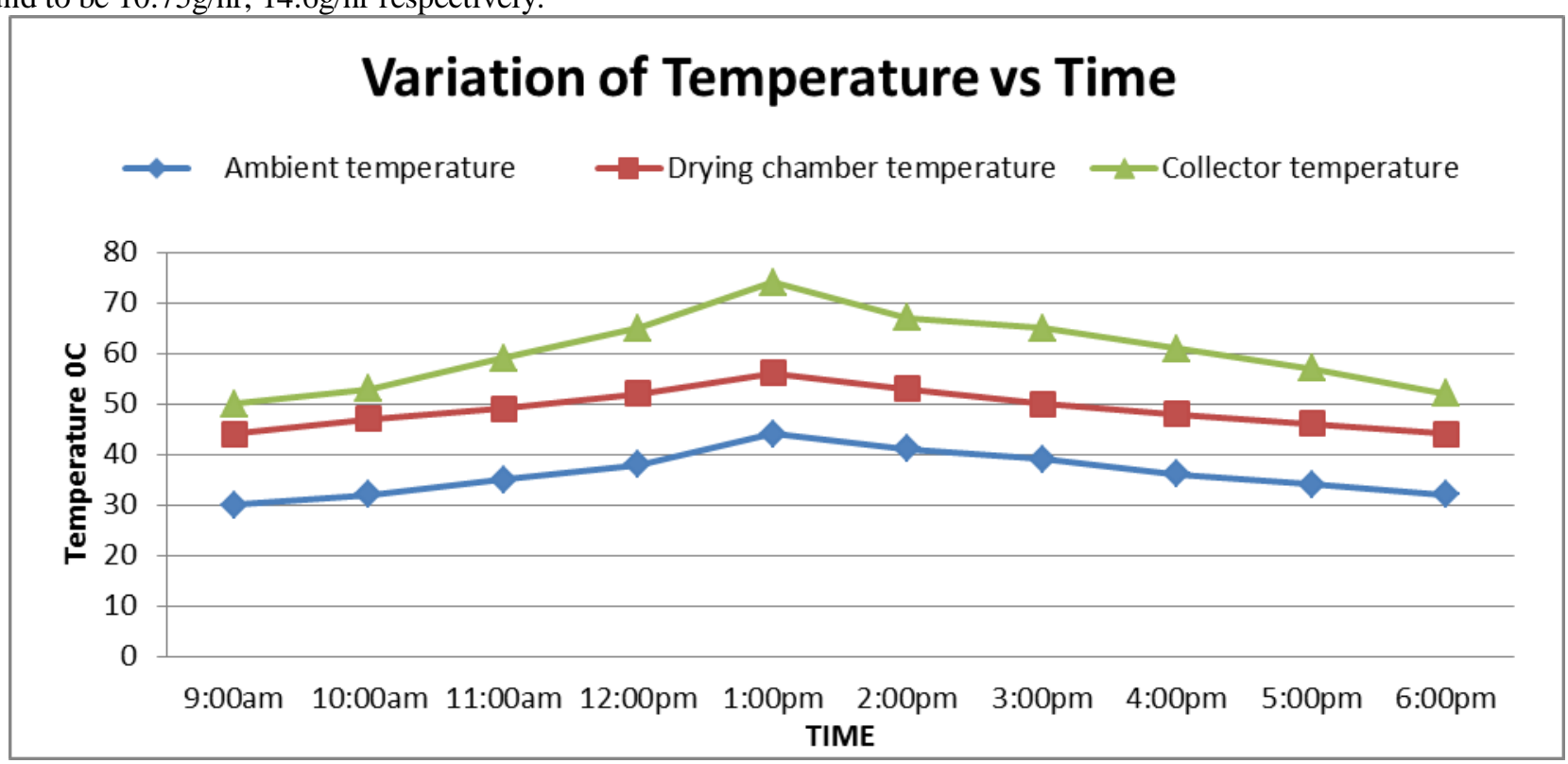

Figure 1. Variation of temperature Vs Time

The trend of the graph shows that the temperature starts to increase from morning and reaches its peak value in the afternoon, where the sun isolation is highest, and starts to descend. After putting the ambient temperature, drying chamber temperature, collector temperature with respect to time it is observed that at $1.00 \mathrm{pm}$ the temperature and solar radiation both are high and after few hours they get slow down and goes back to normal temperature. 


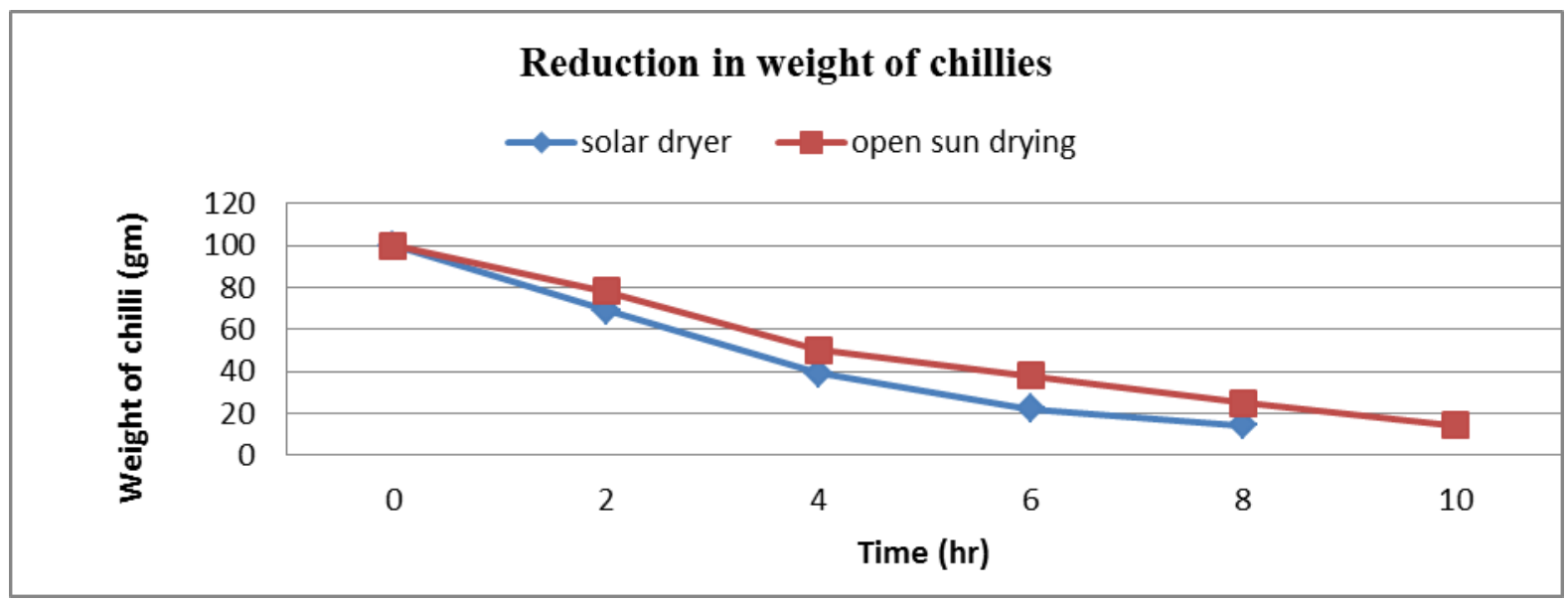

Figure 2. Reduction in weight of chillies

The chillies in the solar dryer took $8 \mathrm{hrs}$ of drying whereas it took $10 \mathrm{hrs}$ of drying in open sun dying. The chillies placed in the open sun has a slower rate of drying as compared to solar dryer. $86 \%$ of moisture was removed from $100 \mathrm{gm}$ of chillies.

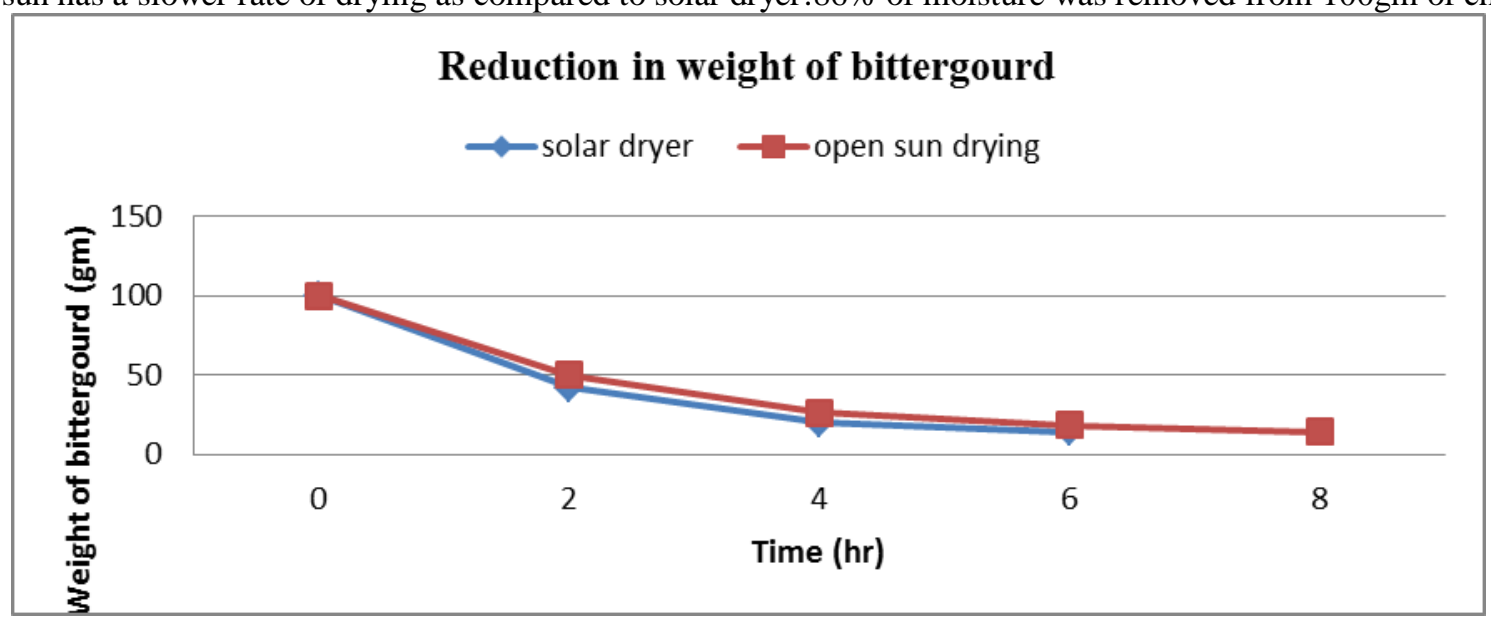

Figure 3. Reduction in weight of bittergourd

Drying time of $6 \mathrm{hrs}$ was required by bitter-gourd placed in solar dryer to reach equilibrium drying stage whereas it took 8 hrs in open sun drying to reach the same. $88 \%$ of moisture was removed.

\section{CONCLUSION}

From the experimentation carried out, the following conclusions were made. The hourly variation of the temperatures inside the solar collector and the drying cabinet are much higher than the ambient temperature during the most part of the experimental period. The solar dryer can raise the ambient air temperature to a considerable high value for increasing the drying rate of vegetables. The product inside the dryer requires less attention, like attack by rain or pest, compared with those in the open sun drying. Although the dryer is used to dry vegetables like chilli, bitter gourd it can be used to dry other agricultural products. The capital cost involved in the construction of a solar dryer is much lower to that of electrical dryer. The temperatures inside the solar collectors are about two times higher than the ambient temperatures. The maximum temperature of the solar flat plate collector is found to be $74^{\circ} \mathrm{C}$ with corresponding ambient temperature of $42^{\circ} \mathrm{C}$ and the maximum drying cabinet temperature is found to be $56^{\circ} \mathrm{C}$ The temperature rise inside the drying cabinet is $50^{\circ} \mathrm{C}$ to $56^{\circ} \mathrm{C}$ after $12.00 \mathrm{hr}$ (noon) i.e. during peak hours and is almost uniform across the trays with time. Thermal efficiency of solar collector is found to be $38 \%$. and the drying efficiency of solar dryer is found to be $15 \%$. Drying rate of chilli, bitter gourd are found to be $10.75 \mathrm{~g} / \mathrm{hr}, 14.6 \mathrm{~g} / \mathrm{hr}$ respectively. This indicates that the dryer exhibits sufficient ability to dry vegetable items at a reasonably rapid rate. The proposed dyer is useful to dry vegetables. It can be used to replace electrical and conventional dryer in semi-urban and rural areas of India. The performance of existing solar dryers can still be improved upon especially in the aspect of reducing the drying time, and probably storage of heat energy within the system by increasing the size of the solar collector. 


\section{REFERENCE:}

[1] A Borah (2015) "Drying kinetics of whole and sliced turmeric rhizomes in solar conduction dryer"Information Processing in Agriculture ,Vol 2,Issue 2,September 2015

[2] Ahmed Abed Gatea, et al., (2010), "Design, construction and performance evaluation of solar maize dryer.” Journal of Agricultural Biotechnology and Sustainable Development Vol. 2(3), pp. 039-046, March 2010

[3] Akinola, A.O. 1999. Development and Performance Evaluation of a Mixed-Mode Solar Food Dryer. M. Eng. Thesis, Federal University of Technology, Akure, Nigeria.

[4] Basumatary, B., Roy, M., Basumatary, D., Narzary, S., Deuri, U., Nayak, P. and Kumar, N.,(2013). Design ,“Construction and Calibration of Low Cost Solar Cabinet Dryer". International Journal of Environmental Engineering and Management, 4(4): 351-358.

[5] Chandrakumar B Pardhi and Jiwanlal L Bhagoria, Development and performance evaluation of mixed-mode solar dryer with forced convection.International Journal of Energy and Environmental Engineering.2 (23):1-8,2013.

[6] Darshit Parikh*, G. D. Agrawal "Solar drying in hot and dry climate Jaipur” International Journal Of Renewable Energy Research, IJRER D.Parikh, G.D.Agrawal, Vol.1, No.4, pp.224-231,2011

[7] Dhanushkodi, S., Wilson, V. H. and Sudhakar, K. (2014). Thermal Performance Evaluation of Indirect Forced Cabinet Solar Dryer for Cashew Drying. American-Eurasian J. Agric. \& Environ. Sci., 14(11): 1248-1254.

[8] Fabio Struckmann. et al., (2008) “Analysis of Flat Plate Solar Collector.” International Journal of Research in Advent Technology, Vol.2, No.2, February 2008 E-ISSN: 2121-4637

[9] Forson, F. K., Nazha, M. A. A., Akuffo, F. O. and Rajakaruna, H. (2007). Design of Mixed-Mode Natural Convection Solar Crop Dryers: Application of Principles and Rules of Thumb. Journal of Renewable Energy, 32(14): 2306-2319

[10] M S Aiswarya . "Economical analysis of solar dryer with pcm for drying agricultural products" International Journa of Science and EngineeringVolume 3, Special Number ICRAESM - 2015PP: 124-134 @IJSE ISSN: 2347-2200 